\title{
Spine imaging after lumbar disc replacement: pitfalls and current recommendations Yohan Robinson* and Bengt Sandén
}

\author{
Address: Uppsala University Hospital, Institute for Surgical Sciences, Department of Orthopaedics, Uppsala, Sweden \\ Email: Yohan Robinson* - yohan.robinson@surgsci.uu.se; Bengt Sandén - bengt.sanden@surgsci.uu.se \\ * Corresponding author
}

Published: 20 July 2009

Patient Safety in Surgery 2009, 3:15 doi:10.1 186/1754-9493-3-15

This article is available from: http://www.pssjournal.com/content/3/I/I5

(C) 2009 Robinson and Sandén; licensee BioMed Central Ltd.

This is an Open Access article distributed under the terms of the Creative Commons Attribution License (http://creativecommons.org/licenses/by/2.0), which permits unrestricted use, distribution, and reproduction in any medium, provided the original work is properly cited.
Received: 9 April 2009

Accepted: 20 July 2009

\begin{abstract}
Background: Most lumbar artificial discs are still composed of stainless steel alloys, which prevents adequate postoperative diagnostic imaging of the operated region when using magnetic resonance imaging (MRI). Thus patients with postoperative radicular symptoms or claudication after stainless steel implants often require alternative diagnostic procedures.

Methods: Possible complications of lumbar total disc replacement (TDR) are reviewed from the available literature and imaging recommendations given with regard to implant type. Two illustrative cases are presented in figures.

Results: Access-related complications, infections, implant wear, loosening or fracture, polyethylene inlay dislodgement, facet joint hypertrophy, central stenosis, and ankylosis of the operated segment can be visualised both in titanium and stainless steel implants, but require different imaging modalities due to magnetic artifacts in MRI.

Conclusion: Alternative radiographic procedures should be considered when evaluating patients following TDR. Postoperative complications following lumbar TDR including spinal stenosis causing radiculopathy and implant loosening can be visualised by myelography and radionucleotide techniques as an adjunct to plain film radiographs. Even in the presence of massive stainless steel TDR implants lumbar radicular stenosis and implant loosening can be visualised if myelography and radionuclide techniques are applied.
\end{abstract}

\section{Background}

Total disc replacement (TDR) is an evolving surgical option for patients with degenerative disc disease $[1,2]$. The appearance of disc arthroplasty has required radiologists to contend with a new entity of spinal implants. Many fusion devices are made of titanium or carbon, howewer the currently available lumbar TDR-implants are made of stainless steel, which obscures imaging when using MR-diagnostics (Table 1).
It is widely accepted that lumbar disc arthroplasty is associated with several access- and implant-associated complications. Unfortunately imaging modalities after TDR cannot simply be transferred from fusion patients. In this review the complications following total disc replacement are discussed and guidelines for imaging following lumbar disc arthroplasty are provided. 
Table I: Alloy and articulation specifics of available lumbar TDR implants

\begin{tabular}{lllll}
\hline Implant name & Charité III & ProDisc & Maverick & Activ L \\
\hline Manufacturer & DePuy & Synthes & Medtronic & B. Braun \\
\hline Alloy & $\mathrm{CoCr}$ & $\mathrm{CoCr}$ & $\mathrm{CoCr}$ & $\mathrm{CoCr}$ \\
\hline Articulation & Non-constrained PE inlay & Semi-constrained PE-inlay & Metal-metal & Semi-constrained PE-inlay \\
\hline
\end{tabular}

\section{Imaging modalities after lumbar total disc replacement} All commercially available lumbar artifical discs are composed of a stainless steel core with titanium surfacing (Table 2). This has implications on the accuracy of postoperative magnetic resonance (MR) diagnostics. Sekhon et al [3] compared the diagnostic quality of MR-imaging with regard to detection of central and foraminal spinal stenosis after cervical disc replacement. They found that only titanium devices allow a proper postoperative visualisation of neural structures at the operated and adjacent levels. Matsuura et al [4] investigated the artifact size of different metals/alloys in MR imaging and found zirconia and aluminium to cause the least artifacts, followed by pure titanium and titanium alloys. Greatest artifacts were caused by stainless steel. Fast-spin echo sequences with lower voxel-size may minimise the artefacts, but stainless steel still has an incomparably worse effect on image quality [5].

Myelography alone and later combined with CT has for many years been the primary diagnostic means in suspected lumbar spinal stenosis. Myelographic findings in central canal stenosis include complete or partial block to the contrast column, appearing as an hour-glass constric- tion on the AP view. There appears to be poor correlation between clinical symptoms and findings at myelography, with myelography commonly showing more abnormalities than would be expected [6,7], although some authors found a block to the flow of contrast medium to be a good predictor of successful outcome following spinal decompression [8].

Scintigraphy with 99mTc radionuclide tagged white blood cells can be a helpful means in diagnosing suspicious infections [9]. 99mTc-hexamethylpropylene amine oxime (HMPAO) is generally more sensitive for the detection of acute osteomyelitis than of chronic osteomyelitis (with a high sensitivity $97.7 \%$ and a specificity of $96.8 \%$ ) [10]. 99mTc-HMPAO is also able to separate septic from aseptic bone lesions [11]. Leukocyte imaging can be applied to chronic osteomyelitis (including infected joint prostheses). $111 \mathrm{In}$-Oxine is preferred over 99mTcHMPAO in such a case because it can be performed simultaneously with 99mTc-stannous fluoride colloid scanning for the assessment of bone marrow involvement (mismatched defects identify infectious foci). Infected orthopaedic hardware will have increased uptake of 111 In-

Table 2: Imaging guidelines after lumbar total disc replacement with regard to implant alloy

\begin{tabular}{lll}
\hline Complication/Alloy & Titanium & Stainless steel (CoCr) \\
\hline Metallosis/PE wear loosening & Plain x-ray, scintigraphy, PET-CT & Plain x-ray, scintigraphy, PET-CT \\
\hline Implant failure/fracture & Plain x-ray, CT & Plain x-ray, CT \\
\hline Implant/Core dislocation & Plain x-ray, CT & Plain x-ray, CT \\
\hline Infection & MR, PET-CT, radiolabelled white blood cell & $\begin{array}{l}\text { PET-CT, radiolabelled white blood cell } \\
\text { scintigraphy }\end{array}$ \\
\hline Late facet degenerationy
\end{tabular}

First-line diagnostics appear first. 
oxine, whereas activity will be normal or decreased in healthy or loose prostheses [10].

Postoperative low-grade-infection or implant loosening can be hard to visualise. As in hip or knee arthroplasty radionuclide scintigraphy has some value with regard to sensitivity, but has lower specificity with regard to loosening or low-grade infection. Gallium 67 scans have a sensitivity and specificity of $89 \%$ and $85 \%$ [12].

In the last years the increased availability of positron emission tomography (PET) enabled postoperative diagnostics with greater specificity for infection. Gratz et al [13] found fluorine-18 fluorodeoxyglucose (FDG) hybrid PET superior to MRI, 67Ga citrate and 99mTc-methylene diphosphonate (MDP), especially in patients with lowgrade spondylitis, adjacent soft tissue infections and advanced bone degeneration. To visualise increased bone turnover 18F-flouride-PET is an option, and found helpful to diagnose aseptic artificial knee joint loosening [14]. There is no clinical evidence available with regard to PET after TDR, but is very likely that this imaging modality will emerge to a more specific diagnostic tool and replace 99mTc-MDP scintigraphy in cases with suspected infections or implant loosening where MRI is obsolete [15].

\section{Indication and options for imaging after lumbar total disc replacement}

Despite the biomechanically appealing concept of motion preservation, lumbar disc arthroplasty is associated with access-related and implant-specific complications. Access and implant related complications can be due to technical errors or may be due to abnormal anatomy [16]. Implant wear and loosening are known to occur in all types of arthroplasty.

\section{a) Access-related complications}

All commercially available FDA-approved lumbar total disc replacements require an anterior access for the implantation of artificial discs. Lumbar discs can be implanted via a transperitoneal or a retroperitoneal approach, of which the latter is favoured by most surgeons. Complications with regard to these accesses are well known and differ not from those of anterior fusion, even though TDR-implantation requires a wider exposure of the disc, which often requires more traction and pressure of retractors on the surrounding tissue [17]. Especially revision-surgery is associated with higher morbidity and mortality compared to the index surgery [18]. Revision may require a transperitoneal approach if the index intervention was retroperitoneal. Then vascular and ureteric stenting may reduce the risk for access-related complications. Nevertheless the availability of a vascular surgeon on call is highly recommended in revision cases [19].
Most access-related complications can be visualised by sonography and abdominal CT with intravenous contrast. In few cases an angiography or an uretherography may be necessary.

\section{b) Infections}

There is no specific data on the occurrence of infection of artificial discs, but early and mid-term infections may occur as likely as in anterior fusion with 0 and $12 \%$ in lumbar instrumented fusion [20]. Nevertheless due to the prevalence of motion and a neo-joint formation, late haematogenic spread infection as known from hip and knee arthoplasty is possible in the immunocompromised TDR patient, with detrimental effects on the patient's health and function.

Postoperative infections of the spine can optimally be visualised by MR with contrast. A sensitivity and specificity of $93 \%$ and $97 \%$ makes the MRI superior to all other radiological imaging modalities [21]. If MRI-scans are not available or stainless steel implants were used radionuclide imaging should be used to reveal focal increased uptake. If available PET-CT scans should be considered to diagnose a suspicious postoperative spinal infection, since PET has a higher specificity than radionuclide scintigraphy.

\section{c) Implant dislocation and polyethylene inlay dislodgment}

Daly et al presented a case series of five anterior dislocations of the Charité (Link) or the AcroDisc (DePuy) disc prosthesis causing compression and erosion of vascular structures. In figure 1 a case with a posterior dislocation of the inferior plate of an artificial disc is presented.

Mobile polyethylene cores can dislocate, too, and can cause compression to anterior abdominal or pelvic structures. This is especially true in non-constrained PE inlays (i.e. Charité TDR) Mathew et al [22] presented a case of an anterior polyethylene dislocation after lumbar TDR (Charité), which was then revised and fused with an anterior standalone cage. Within the case series by Kurtz et al [23] were 2 further cases and in the series of Leary et al [16] one case of anterior core dislocations. This complication required in all cases anterior PE core extraction and fusion. Reposition or exchange of the PE core alone is not recommended due to the prevalent biomechanical failure of the implant with risk of recurrence of dislocation.

Implant dislocation can easily be diagnosed with plain radiographs (figure 1 ). This is also true for PE core dislocations, since the PE-core contains dense markers in the available lumbar implants. 


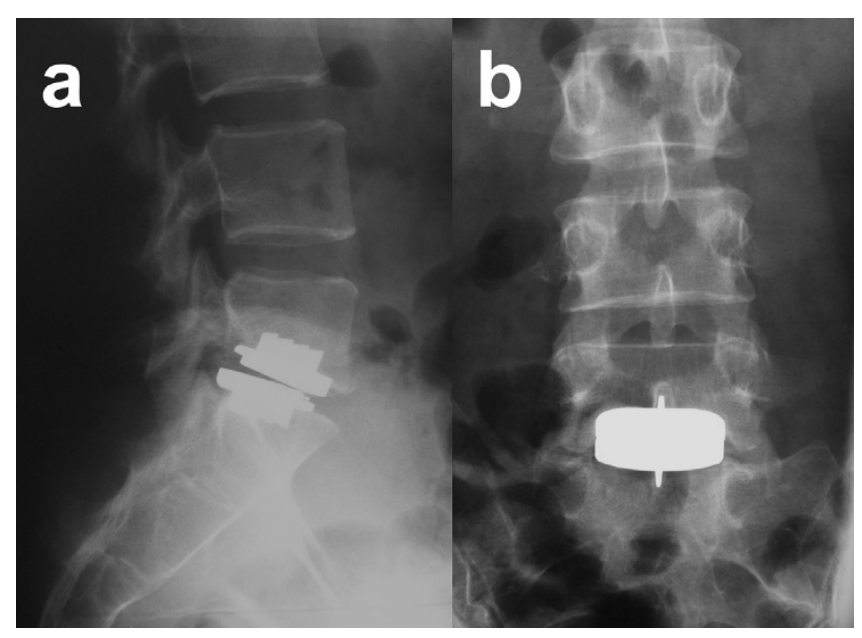

Figure I

A 42-year old female patient with degenerative disc disease received implantation of an artificial disc at L5-S I (Prodisc, Synthes). Postoperative acute bilateral SI-pain without motor deficit could be explained by posterior dislocation of the inferior plate and a subsidence of the cranial plate of the disc prosthesis $(a, b)$. This could clearly be visualised on plain radiographs. No dislocation of the PE inlay occurred which can be seen in the radiographic marker, being still in place. This patient was treated with a conversion into anterior fusion at L5-SI with pain relief at the I year follow-up.

\section{d) Implant failure/fracture}

The long-term investigation of the first implanted lumbar discs ( $\mathrm{n}=53$, mean follow-up 17.3 years; Charité, Link) by Putzier et al [24] included 7 implant fractures resulting in segmental fusion, all of which occurred with the earlier Charité II-model. Of these only one case underwent surgical revision requiring secondary fusion due to intractable pain. These cases show that the chosen implant has to stand a continuous load, requiring enduring metal alloys and stable implant design to provide a lasting product.

Implant fractures are mostly visible on plain radiographs.

\section{e) Implant loosening/wear}

Since implant wear has for decades been a major issue in hip and knee-arthroplasty it is not surprising that other weight-bearing implants with articulating surfaces - as in lumbar disc prostheses - will have to deal with implant wear and loosening, too. Punt et al [25] retrieved 16 artificial discs (SB Charité III, DePuy) which where explanted due to intractable pain after a mean of 8 years. They found polyethylene (PE)-wear debris causing chronic inflammation due to mononuclear macrophage and giant-cell activation. Kurtz et al [26] investigated 38 artificial discs (SB Charité III, DePuy) that were explanted in patients with therapy-resistant chronic pain after an average of 7.3 years (range 2.0-16.1). They found a positive correlation between PE inlay dome penetration and implantation time $(\mathrm{r}=0.46, \mathrm{p}=0.004)$ and an average penetration rate of $0.5 \mathrm{~mm} /$ year (range $0.01-0.18 \mathrm{~mm} /$ year). These results could be validated in a PE-wear in vitro model [26].

Metal-metal articulations are known to cause metallosis with chronic inflammation leading to implant loosening [27]. François et al [28] presented a case of a loosened lumbar disc prosthesis with metal-metal combination (Maverick, Medtronic) one year after implantation causing persistent pain. They found in situ a loosening of the superior endplate and histologically typical signs of metallosis in the surrounding scar tissue. Cavanaugh et al [29] found similar hypergranulation patterns without histological metallosis surrounding a cervical explanted artificial disc causing re-stenosis 6 months after implantation. Implant loosening due to PE or metal wear is a known problem in TDR. Unfortunately not only loosening, but also symptomatic re-stenosis due to granulation caused by PE debris or metallosis were found.

Diagnostics of implant loosening range from standard plain radiographs - revealing radiolucencies around the implant - to scintigraphy and PET, showing increased metabolism in the bone-implant interface.

\section{f) Central or lateral stenosis due to facet degeneration}

The case in figure 2 is a typical example of bi-radicular stenosis after disc replacement. Due to remaining annulus a progressive degeneration of the facet joints most likely caused stenosis leading to nerve root compression one year postoperatively. Postoperative pain has been described in long term studies, and some authors relate this to facet degeneration to hyperlordosation stressing the importance of implant positioning on patient outcome [30]. Park et al [31] found in about 30\% of the cases progressive facet degeneration, which was more common in women, malposition of the implant in the frontal plane and multilevel TDR.

MR diagnostics are the gold-standard for investigation of spinal canal pathologies. In cases where this is not possible - i.e. stainless steel TDR - other modalities as CT and myelography have to be considered.

\section{g) Implant malpositioning}

Bendo et al [32] found the midline retroperitoneal access associated with less sagittal implant misplacements than the pararectal lateral retroperitoneal access $(p=0.021)$, but this did not have any impact on clinical functional outcome, determined with the Oswestry disability index ( $p=0.92)$. Rauschmann et al [33] presented in a cadaver study improved positioning of the lumbar artificial disc if navigation was applied compared to fluoroscopy $(n=30)$. 


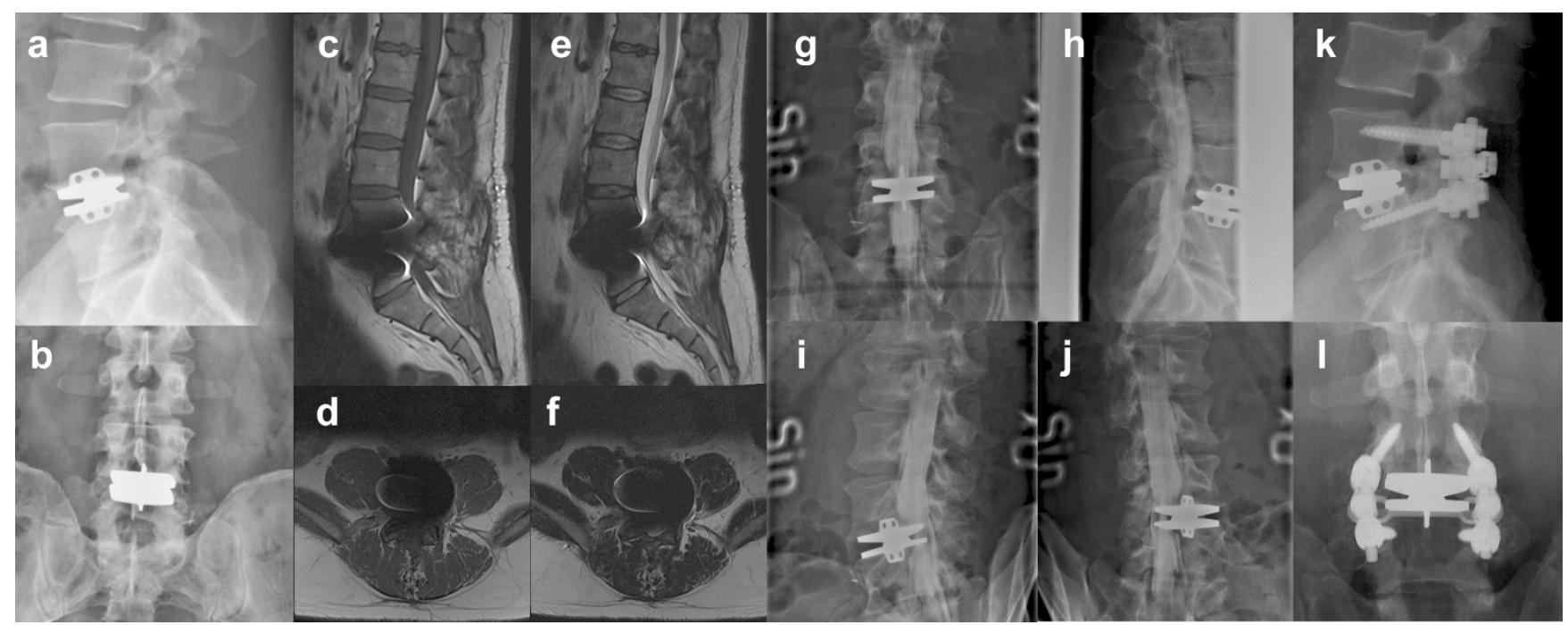

\section{Figure 2}

46-year old male patient with increasing bilateral sensomotor deficit at L5 one year postoperatively after implantation of a metal-on-metal stainless steel artificial disc (Maverick, Medtronic) at L4-L5 (a, b) presented major artifacts on MR imaging in TI (c, d) and T2 (e, f). Neurophysiological investigations revealed acute bilateral L5compression. Leading diagnostic procedure that could visualise a bilateral compression of L5 was plain myelography, which revealed an anterior compression of the thecal sac $(g, h)$ and compression of the right (i) and left (j) L5-root. Therefore a posterior decompression and instrumented posterolateral fusion was performed while keeping the implant in situ ( $k$, I). Intraoperatively facet hypertrophy and posterior bulging of remaining annulus was seen. The sensomotor deficit resolved completely. The patient regained function and returned to work.

Malpositioning can be due to minimal malrotation of the image intensifier, anomalities in the spinal process anatomy, and the parallax effect in intraoperative fluoroscopy [34]. Navigation can therefore have significant impact on the quality and durability of artificial discs in the future.

To control implant positioning plain radiographs are usually sufficient.

\section{h) Segmental ankylosis}

Long-term investigations failed to present preservation of motion of the operated segment. Putzier et al [24] found that $60 \%$ of all treated patients $(n=53)$ had spontaneous fusion of the treated segment after a mean follow-up of 17-years (Charité, Link). Interestingly these patients were better than those with remaining motion with regard to functional measures (ODI, p < 0.05) and pain (VAS, p < $0.05)$. Thus fusion should be viewed as a natural course of motion preservation treatment and not as a complication.

To diagnose fusion either a CT-scan showing ankylosis or dynamic radiographs excluding remaining segmental mobility are required.

\section{i) Progressive implant subsidence}

In osteoporosis or poor bone quality, years after the original implantation, the artificial disc can subside into the endplates, causing secondary implant dislocation and increasing pain. To avoid this complication the choice of the largest possible implant and a placement close to the rim of the endplates is recommended [30].

To visualise implant subsidence plain radiographs are sufficient. If an osteoporotic vertebral endplate fracture is suspected, radionuclide scans may show increased uptake of the fractured vertebra.

\section{Conclusion}

Postoperative imaging of lumbar total disc replacement requires alternative imaging techniques to conventional MRI-diagnostics. All currently available lumbar artificial discs contain stainless steel alloys, and, therefore, generate major artefacts on MRI. Alternative imaging modalities include plain film radiographs, myelography and radionucleotide imaging. These imaging modalities should be utilised in cases with suspected postoperative complications after lumbar TDR.

The appearance of artificial discs on the implant market meant a drawback in postoperative radiological transparency with regard to MR-diagnostics, since all lumbar disc prostheses are still based on stainless steel alloys, thus causing major artefacts. Other imaging modalities are available and are in the first line of choice in cases with 
suspected postoperative complications after lumbar TDR. Until lumbar titanium artificial discs are available postoperative imaging of the operated segment requires altered radiological strategies.

\section{Competing interests}

The authors have no competing interests with regard to the publication of this manuscript.

\section{Authors' contributions}

YR wrote the manuscript and BS critically revised it. Both authors read and approved the final version of the manuscript

\section{Acknowledgements}

Written informed consent was obtained from the patients presented in this article and is available to the editor-in-chief by request.

\section{References}

I. Bono CM, Garfin SR: History and evolution of disc replacement. Spine J 2004, 4(6 Suppl): I45S-I50S.

2. Gibson JN, Waddell G: Surgery for degenerative lumbar spondylosis. Cochrane. Database Syst Rev 2005, 4:CD00I 352.

3. Sekhon LH, Duggal N, Lynch JJ, Haid RW, Heller JG, Riew KD, Seex $\mathrm{K}$, Anderson PA: Magnetic resonance imaging clarity of the Bryan, Prodisc-C, Prestige LP, and PCM cervical arthroplasty devices. Spine 2007, 32:673-80.

4. Matsuura H, Inoue T, Konno H, Sasaki M, Ogasawara K, Ogawa A: Quantification of susceptibility artifacts produced on highfield magnetic resonance images by various biomaterials used for neurosurgical implants. Technical note. J Neurosurg 2002, 97: 1472-5.

5. Suh JS, Jeong EK, Shin KH, Cho JH, Na JB, Kim DH, Han CD: Minimizing artifacts caused by metallic implants at MR imaging: experimental and clinical studies. AJR Am J Roentgenol 1998, |7|:|207-|3.

6. Amundsen T, Weber H, Lilleas F, Nordal HJ, Abdelnoor HJ, Magnaes $\mathrm{B}$ : Lumbar spinal stenosis. Clinical and radiologic features. Spine 1995, 20: II78-86.

7. Jonsson B, Annertz M, Sjöberg C, Strömqvist B: A prospective and consecutive study of surgically treated lumbar spinal stenosis. Part I: Clinical features related to radiographic findings. Spine 1997, 22:2932-7.

8. Herno A, Airaksinen O, Saari T, Miettinen $\mathrm{H}$ : The predictive value of preoperative myelography in lumbar spinal stenosis. Spine 1994, 19:1335-8.

9. Seabold JE, Nepola JV: Imaging techniques for evaluation of postoperative orthopedic infections. Q J Nucl Med 1999, 43:2I-8.

10. Wolf G, Aigner RM, Schwarz T: Diagnosis of bone infection using 99mTc HMPAO labelled leukocytes. Nucl Med Commun 2001, 22: $|20|-1206$

II. Datz FL, Seabold JE, Brown ML, Forstrom LA, Greenspan BS, McAfee JG, Palestro CJ, Schauwecker DS, Royal HD: Procedure guideline for technetium-99m-HMPAO-labeled leukocyte scintigraphy for suspected infection/inflammation. Society of Nuclear Medicine. J Nucl Med 1997, 38:987-90.

12. Bruschwein DA, Brown ML, McLeod RA: Gallium scintigraphy in the evaluation of disk-space infections: concise communication. J Nucl Med 1980, 2 I:925-7.

13. Gratz S, Rennen HJ, Boerman OC, Oyen WJ, Mast P, Behr TM, Corstens FH: 99mTc-HMPAO-labeled autologous versus heterologous leukocytes for imaging infection. J Nucl Med 2002, 43:918-24.

14. David T: Revision of a Charité artificial disc 9.5 years in vivo to a new Charité artificial disc: case report and explant analysis. Eur Spine J 2005, I 4:507-I I. Sterner T, Pink R, Freudenberg L, Jentzen T, Quitmann H, Bockisch A, Löer F: The role of [18F]fluoride positron emission tomography in the early detection of aseptic loosening of total knee arthroplasty. Int J Surg 2007, 5:99-104.

15. van Ooij A, Kurtz SM, Stessels F, Noten H, van Rhijn L: Polyethylene wear debris and long-term clinical failure of the Charité disc prosthesis: a study of 4 patients. Spine 2007, 32:223-9. Zhuang H, Yang H, Alavi A: Critical role of I 8F-labeled fluorodeoxyglucose PET in the management of patients with arthroplasty. Radiol Clin North Am 2007, 45:7I I-8, vii.

16. Leary SP, Regan J], Lanman TH, Wagner WH: Revision and explantation strategies involving the CHARITE lumbar artificial disc replacement. Spine 2007, 32:100I-II.

17. Tropiano P, Huang RC, Girardi FP, Cammisa FP Jr, Marnay T: Lumbar total disc replacement. Seven to eleven-year follow-up. J Bone Joint Surg Am 2005, 87:490-6.

18. Brau SA, Delamarter RB, Kropf MA, Watkins RG 3rd, Williams LA, Schiffman ML, Bae HW: Access strategies for revision in anterior lumbar surgery. Spine 2008, 33:1662-7.

19. Wagner WH, Regan JJ, Leary SP, Lanman TH, Johnson JP, Rao RK, Cossman DV: Access strategies for revision or explantation of the Charité lumbar artificial disc replacement. J Vasc Surg 2006, 44:1266-72.

20. Beiner JM, Grauer J, Kwon BK, Vaccaro AR: Postoperative wound infections of the spine. Neurosurg Focus 2003, I5:EI4.

21. Szypryt EP, Hardy JG, Hinton CE, Worthington BS, Mulholland RC: A comparison between magnetic resonance imaging and scintigraphic bone imaging in the diagnosis of disc space infection in an animal model. Spine 1988, 13:1042-8.

22. Mathew P, Blackman M, Redla S, Hussein AA: Bilateral pedicle fractures following anterior dislocation of the polyethylene inlay of a ProDisc artificial disc replacement: a case report of an unusual complication. Spine 2005, 30:E3 II-4.

23. Kurtz SM, Peloza J, Siskey R, Villarraga ML: Analysis of a retrieved polyethylene total disc replacement component. Spine J 2005, 5:344-50.

24. Putzier M, Funk JF, Schneider SV, Gross C, Tohtz SW, KhodadadyanKlostermann C, Perka C, Kandziora F: Charité total disc replacement - clinical and radiographical results after an average follow-up of 17 years. Eur Spine J 2006, 15:183-95.

25. Punt IM, Visser VM, van Rhijn LW, Kurtz SM, Antonis J, Schurink GW, van Ooij A: Complications and reoperations of the SB Charité lumbar disc prosthesis: experience in $\mathbf{7 5}$ patients. Eur Spine J 2008, I7:36-43.

26. Kurtz SM, Patwardhan A, MacDonald D, Ciccarelli L, van Ooij $A$, Lorenz M, Zindrick M, O'Leary P, Isaza J, Ross R: What is the correlation of in vivo wear and damage patterns with in vitro TDR motion response? Spine 2008, 33:48I-9.

27. Korovessis P, Petsinis G, Repanti M, Repantis T: Metallosis After Contemporary Metal-on-Metal Total Hip Arthroplasty. Five to Nine-Year Follow-up. J Bone Joint Surg Am 2006, 88: I I 83-I 191.

28. François J, Coessens R, Lauweryns P: Early removal of a Maverick disc prosthesis: surgical findings and morphological changes. Acta Orthop Belg 2007, 73: I22-7.

29. Cavanaugh DA, Nunley PD, Kerr EJ 3rd, Werner DJ, Jawahar A: Delayed hyper-reactivity to metal ions after cervical disc arthroplasty: a case report and literature review. Spine 34:E262-5

30. Baur-Melnyk A, Birkenmaier C, Reiser MF: Lumbar disc arthroplasty: indications, biomechanics, types, and radiological criteria. Radiologe 2006, 46:768-78.

31. Park CK, Ryu KS, Jee WH: egenerative changes of discs and facet joints in lumbar total disc replacements using ProDisc II: minimum two-year follow-up. Spine 2008, 33:DI755-6I.

32. Bendo JA, Quirno M, Errico T, Spivak JM, Goldstein J: A comparison of two retroperitoneal surgical approaches for total disc arthroplasty of the lumbar spine. Spine 2008, 33:205-9.

33. Rauschmann MA, Thalgott J, Fogarty M, Nichlos M, Kleinszig G, Knap $M$, Kafchitsas K: Insertion of the artificial disc replacement: a cadaver study comparing the conventional surgical technique and the use of a navigation system. Spine 2009, 34:III0-5.

34. Petilon J, Hardenbrook M, Sukovich W: The effect of parallax on intraoperative positioning of the Charit $\beta$ artificial disc. J Spinal Disord Tech 2008, 21 :422-9. 